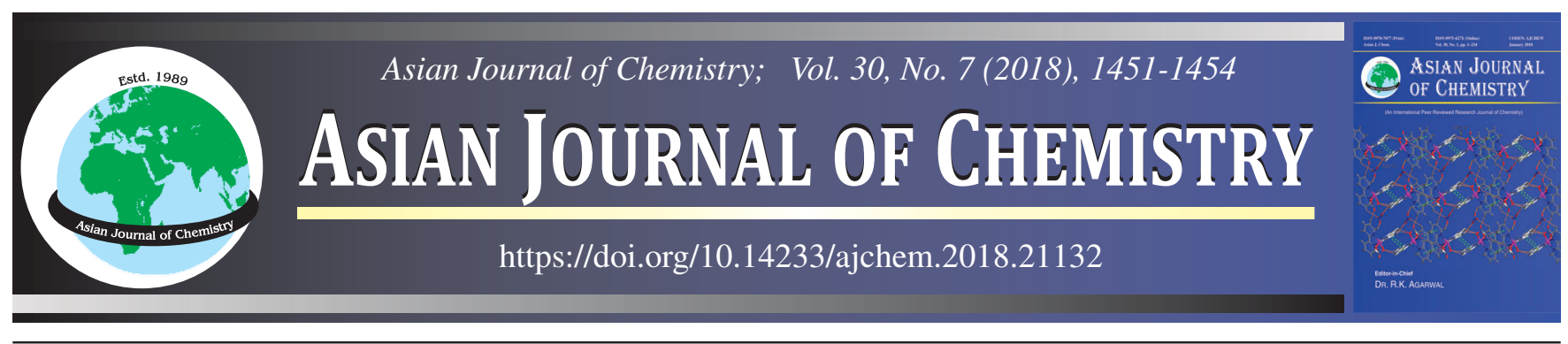

\title{
Digital Image-Based Colorimetry for Enhancement of Arsenic(III) Determination
}

Jin Hoong Leong ${ }^{1}$, Keat Khim Ong ${ }^{2, *}$, Wan Yunus Wan Md Zin $^{3}$, Fitrianto Anwar ${ }^{4}$, Chin Chuang Teor ${ }^{5}$, Jahwarhar IzUan Abd Rashid ${ }^{2}$ and Mansor Ahmad ${ }^{4}$

${ }^{1}$ Faculty of Engineering, Universiti Pertahanan Nasional Malaysia, Kem Sungai Besi, 57000 Kuala Lumpur, Malaysia

${ }^{2}$ Centre for Defence Foundation Studies, Universiti Pertahanan Nasional Malaysia, Kem Sungai Besi, 57000 Kuala Lumpur, Malaysia ${ }^{3}$ Faculty of Defence Science Technology, Universiti Pertahanan Nasional Malaysia, Kem Sungai Besi, 57000 Kuala Lumpur, Malaysia ${ }^{4}$ Faculty of Science, Universiti Putra Malaysia, 43400 UPM Serdang, Selangor, Malaysia

${ }^{5}$ Malaysian Agricultural Research and Development Institute Headquarter, G.P.O. Box 12301, 50774 Kuala Lumpur, Malaysia

*Corresponding author: E-mail: ongkhim@upnm.edu.my

Received: 17 November 2017;

Accepted: 27 February 2018;

Published online: 31 May 2018;

AJC-18912

In this report, we describe a simple, rapid and reliable on-site detection method of arsenic(III) using colorimetric method incorporated with image processing technique. The method detection limit $(2.24 \mu \mathrm{g} / \mathrm{L}$ ), accuracy (relative bias of 0.5 to $5.2 \%$ ), precision (relative standard deviations of 0.2 to $3.3 \%$ ) of the developed mathematical model to estimate concentration of arsenic(III) were reported in this study. Interference by various ions were investigated and insignificant interferences were found.

Keywords: Arsenic(III), Colorimetric, Image processing.

L -

\section{INTRODUCTION}

Arsenic and its derivatives have been used in pharmaceutical products, pesticides, alloying agents, semiconductors and metal adhesives [1]. However, inorganic arsenic compounds are categorized in Group 1 (carcinogenic to humans) by the International Agency for Research on Cancer (IARC) [2]. Arsenic can enter our body either by drinking of contaminated water or by the consumption of plants commonly grown in the contaminated area [3]. Environmental exposure to arsenic causes a huge health problem globally [4].

Various arsenic detection techniques were developed [5]. However, most of these methods have limitations such as interference by a large number of ions, low/moderate sensitivity and require heating or extraction from organic solvents, requirement of sample preservations and chemical reduction steps, which may introduce sample contamination [6]. In addition, the samples are required to be transported to a laboratory for the analysis using a sophisticated analytical instrument. These sophisticated analytical techniques need sample preparation before the analysis, which is found to be tedious, time consuming and more reagents are required $[1,7]$.

Therefore, to overcome these disadvantages, a rapid and simple detection method is required to provide an on-site checking of risk level of source water for drinking use and of effluent from small-scale arsenic removal plants with a rapid monitoring tool may be useful. Some kinds of spot test kits for detecting of arsenic using a test strip and a gas-detection tube were reported. These spot tests enable visual determination, but the accuracy is usually low as concentration of arsenic increases exponentially with the increase of colour intensity or colour band length [8]. Thus, there is a need to develop a simple, reliable, highly sensitive method, which would overcome the existing inadequacies in the determination of traces amounts of arsenic.

\section{EXPERIMENTAL}

$1000 \mathrm{mg} / \mathrm{L}$ of As(III) standard solution, silver nitrate, sulfamic acid and zinc powder were obtained from Merck (Germany) and used as received. All chemicals used were of analytical grade.

Preparation of As(III) working standard solutions: Various concentrations ( 0 to $300 \mu \mathrm{g} / \mathrm{L}$ ) of As(III) working standard solutions were freshly prepared from the As(III) stock solution by dilutions using ultrapure water obtained from MilliQ water purification system (Millipore).

Preparation of $5 \%(\mathrm{w} / \mathrm{v})$ silver nitrate solution: A $5 \%$ (w/v) solution of silver nitrate was prepared by dissolving desired amount of silver nitrate in a $100 \mathrm{~mL}$ volumetric flask and made up with ultrapure water.

Preparation of silver nitrate-impregnated filter paper: A round-shaped piece of the paper with a diameter of $2.5 \mathrm{~cm}$ 
was prepared by cutting Whatman filter paper No. 3 . The paper was inserted into the silver nitrate solution for 2 seconds and then dried it by pressing it between two pieces of dry Whatman filter papers with a 100 load for $20 \mathrm{~s}$. This silver nitrate-impregnated filter paper was used as the sensor paper for detection of As(III).

Coloured compound formation: The detection of various concentrations ( 0 to $300 \mu \mathrm{g} / \mathrm{L}$ ) of As(III) was performed in five replications at the optimum conditions as reported by Leong et al. [9] in order to develop a mathematical model for the estimation of concentrations of As(III) in water samples. Briefly, the optimum amount of sulfamic acid was added to a $60 \mathrm{~mL}$ of polypropylene bottle which contained $50 \mathrm{~mL}$ of As(III) working standard solution. The bottle was swirled before adding the optimum amount of zinc powder and swirled again. The impregnated filter paper was subsequently inserted inside the cap of the bottle. The bottle was closed with the cap and swirled gently. The coloured impregnated filter paper was captured and used for image analysis after the optimum period.

Colour image processing: The image processing of the captured images were performed using the method as described by Leong et al. [9] where colour images were captured by a digital camera (Sony Cyber-shot, DSC-W610) at the distance of $15 \mathrm{~cm}$ at constant conditions for all experiments. The images were transformed into Red, Green and Blue (RGB) colour values (0 to 225) using Image $\mathbf{J}$ software and subsequently used for mathematical modelling and statistical analysis.

\section{RESULTS AND DISCUSSION}

Mathematical model development for As(III) determination based on RGB values: A total of 30 experimental runs ( $\mathrm{n}=5$ replicates) at six different concentrations of As(III) ranging from 0 to $300 \mu \mathrm{g} / \mathrm{L}$ were performed using the developed method. Using an image processing software, the images of coloured produced on the impregnated filter paper were analyzed and converted to obtain RGB values. The corresponding relative standard deviations (RSDs) and mean of each RGB values of each concentration are presented in Table- 1 . The RSDs of the RGB values at different concentrations of As(III) range from 1.03 to $4.81 \%$ which less than $5 \%$, indicating that all data are precise and high reproducibility. Table- 1 shows that all RGB values decrease as increasing of As(III) concentration. This indicated that the mean of RGB values are inversely proportional to the concentration of $\mathrm{As}(\mathrm{III})$.

\begin{tabular}{ccccccc}
\multicolumn{7}{c}{ TABLE-1 } \\
\multicolumn{7}{c}{$\begin{array}{c}\text { MEAN OF RGB VALUES USED FOR } \\
\text { MATHEMATICAL MODELLING }\end{array}$} \\
\hline $\begin{array}{c}\text { Known As(III) } \\
\text { conc. }(\mu \mathrm{g} / \mathrm{L})\end{array}$ & \multicolumn{2}{c}{ Mean of colour value } & \multicolumn{4}{c}{ RSD $(\%)$} \\
\cline { 2 - 8 } & $\mathrm{R}$ & $\mathrm{G}$ & $\mathrm{B}$ & $\mathrm{R}$ & $\mathrm{G}$ & $\mathrm{B}$ \\
\hline 0 & 140.84 & 161.01 & 164.02 & 1.03 & 1.04 & 1.27 \\
10 & 138.90 & 152.10 & 158.90 & 2.00 & 2.17 & 3.09 \\
50 & 134.53 & 147.10 & 148.04 & 3.03 & 2.65 & 4.81 \\
100 & 129.90 & 132.50 & 123.56 & 3.32 & 3.06 & 4.21 \\
200 & 120.59 & 125.76 & 94.62 & 3.78 & 3.92 & 3.58 \\
300 & 105.88 & 106.99 & 79.12 & 3.48 & 3.69 & 4.41 \\
\hline
\end{tabular}

$\mathrm{R}=$ Red, $\mathrm{G}=$ Green, $\mathrm{B}=$ Blue
Due to high precision of RGB data, the multiple regression analysis based on RGB values was employed in order to improve the colorimetric detection of arsenic in solutions. In this analysis, the mean of RGB values was used to develop a multiple regression model that can be used to determine the concentration of As(III) concentrations. The multiple regression model has the general form as presented in eqn. 1 :

$$
Y=\beta_{0}+\beta_{1} X_{1}+\beta_{2} X_{2}+\beta_{3} X_{3}+\ldots \ldots . .+\varepsilon
$$

where $\mathrm{X}_{1}, \mathrm{X}_{2}, \mathrm{X}_{3}$ denote the independent variables, $\mathrm{Y}$ stands for the dependent variable, $\beta_{0}, \beta_{1}, \beta_{2}, \beta_{3}$ represent the correlation coefficients and $\varepsilon$ designates the error term. With above equation, the final fitted model and the coefficient of RGB values were obtained and expressed in below equation:

$$
\begin{gathered}
\text { As(III) concentration }=1009-6.70 \text { Red }+ \\
1.13 \text { Green }-1.511 \text { Blue }
\end{gathered}
$$

\section{Analytical performance of As(III) measurement}

Accuracy: The accuracy of developed model for As(III) measurement was evaluated by relative bias (RB) as expressed by the following equation:

$$
\mathrm{RB}(\%)=\left|\frac{\mathrm{d}}{\mathrm{C}_{\mathrm{R}}}\right| \times 100
$$

where $d$ is the difference between the reading of As(III) concentration $(\mu \mathrm{g} / \mathrm{L})$ by the developed model and known As(III) concentration $(\mu \mathrm{g} / \mathrm{L})$ and $\mathrm{C}_{\mathrm{R}}$ is known $\mathrm{As}(\mathrm{III})$ concentration. Overall, low RB was obtained as increasing of As(III) concentration from 10 to $300 \mu \mathrm{g} / \mathrm{L}$ as shown in Table-2. Table2 shows that all the calculated As(III) concentration is almost too close to the references As(III) concentration. The results revealed that the RBs of calculated As(III) using the developed model were relatively low in the range from 0.5 to $5.2 \%$.

TABLE-2

ACCURACY AND PRECISION OF DEVELOPED MODEL TO MEASURE As(III) WITH KNOWN As(III) CONCENTRATION

\begin{tabular}{cccc}
\hline $\begin{array}{c}\text { Known } \\
\operatorname{As}(\mathrm{III})(\mu \mathrm{g} / \mathrm{L})\end{array}$ & $\begin{array}{c}\text { Calculated mean } \\
\operatorname{As}(\mathrm{III})(\mu \mathrm{g} / \mathrm{L})\end{array}$ & $\begin{array}{c}\text { Relative standard } \\
\text { deviation }(\%)\end{array}$ & $\begin{array}{c}\text { Relative } \\
\text { bias }(\%)\end{array}$ \\
\hline 10 & $10.52 \pm 0.350$ & 3.3 & 5.2 \\
50 & $48.64 \pm 2.160$ & 4.4 & 2.7 \\
100 & $103.40 \pm 3.520$ & 3.4 & 3.4 \\
200 & $198.98 \pm 2.367$ & 1.2 & 0.5 \\
300 & $301.420 \pm 0.557$ & 0.2 & 0.5 \\
\hline
\end{tabular}

Precision: In addition, the determination of RSD values was employed to check the precision of the developed model in As(III) determination towards the references method (Table-2). By using 5 replicates of each As(III) concentration, the RSDs values were in the range of $0.2 \%$ to $4.4 \%$. The results indicated that both relative bias and RSDs values were relative low. Due to smaller RB and RSD values obtained in this study, the measurement of As(III) by the developed model can be both accurate and precise.

Linearity: A further validation of developed model was examined by performing a linear regression of calculated As(III) against known As(III) concentration for the five samples ranging from 10 to $300 \mu \mathrm{g} / \mathrm{L}$ (Fig. 1) It was shown that the $\mathrm{R}^{2}$ of the linear regression for the developed model was 0.9998 . 


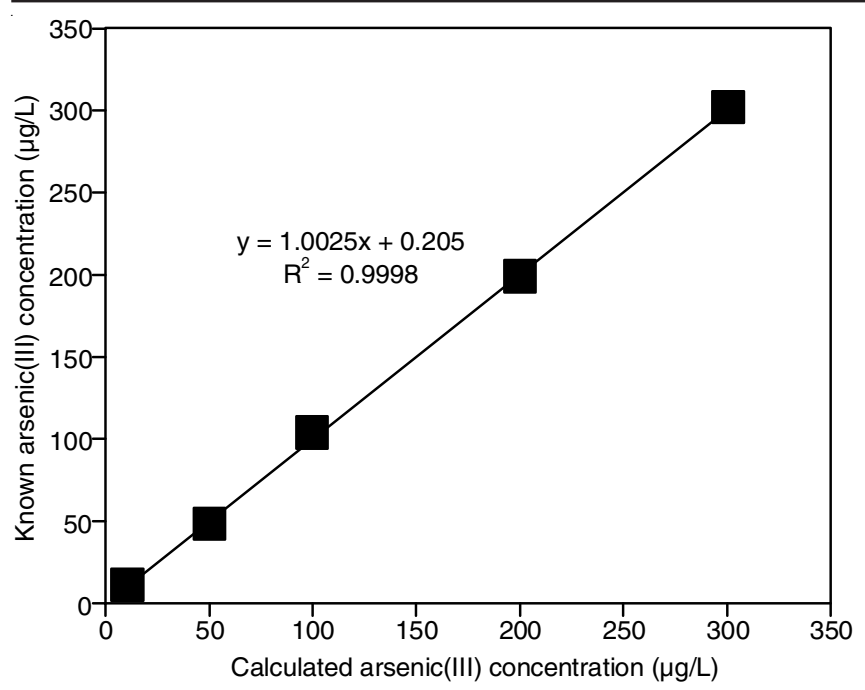

Fig. 1. Linear regression of calculated As(III) against known As(III) concentration

The high value of $\mathrm{R}^{2}$ revealed that the calculated As(III) concentration showed a good correlation with known As(III) concentration, thus validated the developed model to determine As(III) concentration. A similar technique was employed by Carro Perez and Francisca [10] and they concluded that the digital analysis image of paper strips for As(III) measurement is highly correlated $\left(\mathrm{R}^{2}=0.98\right)$ with the standard method.

Method detection limit (MDL): The detection limit of As(III) measurement based on developed model was evaluated using method detection limit (MDL). The method detection limit is the minimum concentration of a substance measured and reported with $99 \%$ confidence that the analyte concentration is greater than zero and is determined from analysis of a sample in a given matrix containing the analyte [11]. In this study, the minimum concentration of As(III) $(10 \mu \mathrm{g} / \mathrm{L})$ was employed to determine the method detection limit of As(III). The method detection limit for As(III) measurement based on developed model was performed by analyzing seven replicates of samples spiked with $10 \mu \mathrm{g} / \mathrm{L}$ of As(III). The method detection limit was calculated based on the following equation:

$$
\text { Method detection limit }=\mathrm{t} \times \mathrm{SD}
$$

where $t=3.14$ is the Student's $t$ value at $99 \%$ confidence level with seven replicates and SD is the standard deviation of the replicate samples. The results of seven replications of the experiments to detect 9 and $10 \mu \mathrm{g} / \mathrm{L}$ of arsenic(III) are presented in Table-3. The mean of $10 \mu \mathrm{g} / \mathrm{L}$ of arsenic(III) was 10.097 $\mu \mathrm{g} / \mathrm{L}$ and recovery of $100.97 \%$. However, the mean of $9 \mu \mathrm{g} / \mathrm{L}$ was only $4.502 \mu \mathrm{g} / \mathrm{L}$ and recovery was also low (45.02\%). In addition, there was a significant difference between $9 \mu \mathrm{g} / \mathrm{L}$ and the calculated arsenic(III) from the developed mathematical model. Consequently, the mean of $10 \mu \mathrm{g} / \mathrm{L}$ was employed to calculate the method detection limit for detection of arsenic(III). The method detection limit was calculated by multiplying 3.14 with the standard deviation of $10 \mu \mathrm{g} / \mathrm{L}$ of arsenic(III) based on eqn. 6 . The method detection limit for detection of arsenic(III) was $2.24 \mu \mathrm{g} / \mathrm{L}$.

Hence, the developed model is able to determine As(III) concentration in the permissible limit of arsenic in drinking water by WHO. The detection limit of $\mathrm{As}(\mathrm{III})$ in this study

\begin{tabular}{lcc}
\hline \multicolumn{3}{c}{ TABLE-3 } \\
DETERMINATION OF ESTIMATED METHOD \\
DETECTION LIMIT OF 10 AND 9 $\mu \mathrm{g} / \mathrm{L}$ OF As(III) \\
\hline & Concentration of As(III) \\
& $9 \mu \mathrm{g} / \mathrm{L}$ & $10 \mu \mathrm{g} / \mathrm{L}$ \\
\hline Mean of calculated As(III) $(\mu \mathrm{g} / \mathrm{L})$ & 4.502 & 10.097 \\
Standard deviation $(\mu \mathrm{g} / \mathrm{L})$ & 0.984 & 0.713 \\
Mean of recovery $(\%)$ & 45.02 & 100.97 \\
$p$-Value of paired sample $t$-test & 0.000 & 0.731 \\
Method detection limit $(\mu \mathrm{g} / \mathrm{L})$ & - & 2.24 \\
\hline
\end{tabular}

was slightly lower $(2.24 \mu \mathrm{g} / \mathrm{L})$ as compared to the previous studies. Devi et al. [12] reported their arsenic field kit was able to detect arsenic as low as 4 ppb using Gutzeit method. Meanwhile, Hu et al. [13] employed the molybdenum method based on the formation of molybdenum blue complexes for detection of $\mathrm{As}(\mathrm{III}) /(\mathrm{V})$ and found that the detection limit was $8 \mu \mathrm{g} / \mathrm{L}$. Using similar principle As detection in this study, Das and Sarkar [14] had achieved $10 \mu \mathrm{g} / \mathrm{L}$ as the lowest detection limit of As(III) but without the use of image processing. Compared to our finding, the detection limit of As(III) measurement could be improved when coupling with image processing technique.

Matrix interferences studies: The efficiency of As(III) determination could be affected by the presence of ions in the real samples. Thus, the matrix interferences studies were performed by spiking synthetic samples contained $10 \mu \mathrm{g} / \mathrm{L}$ of arsenic(III) with each ion individually at two different concentrations (i.e. low and high levels). The concentrations of these interferences ions used ranging from 0.002 to 400 $\mathrm{mg} / \mathrm{L}$ (Table-4). The effect of these ions on the determination of As(III) could be evaluated based on the As(III) recoveries (\%) as shown in Table-4. There is little or no loss of As(III) determination if the recovery value is close to $100 \%$. As it can be seen from Table-4, a good recovery of As(III) was observed which range from 93.84 to $115.07 \%$ either using low or high-level concentration of the interference ions. These results suggested that either low or high-level concentration of the interference ions did not interfere in the determination of $10 \mu \mathrm{g} / \mathrm{L}$ of As(III) using our developed model. This finding was supported with the Paired Sample t-test between known concentration of As(III) and calculated concentration of As(III) after spiked with interference ions at both levels. Due to the $p$ value of paired sample t-test for all interference metal ions at both levels was higher than $0.05(p>0.05)$, there were no significant difference between known concentration of As(III) and calculated As(III). Interestingly, at a high-level concentration of $\mathrm{Na}^{+}(300 \mathrm{mg} / \mathrm{L}), \mathrm{Cl}^{-}(200 \mathrm{mg} / \mathrm{L}), \mathrm{SO}_{4}{ }^{2-}(200 \mathrm{mg} / \mathrm{L})$ and $\mathrm{NO}^{-}(400 \mathrm{mg} / \mathrm{L})$ in the spiked samples are still exhibit a high recovery of As(III). Comparable with the study of Salman et al. [15] that claimed that the interferences metal ions such as $\mathrm{Na}^{+}, \mathrm{K}^{+}, \mathrm{SO}_{4}{ }^{2-}, \mathrm{Cl}^{-}$gave insignificant effect on the determination of As in water. Similar observation was reported by Hagiwara et al. [16] and they concluded that the major and minor metal ions typically found in fresh water did not interfere with As recovery. This study also demonstrates that the determination of As(III) using this method could be applied to the water samples which contain the interference ions used in this study. Thus, it can be concluded that the combination of colorimetric 


\begin{tabular}{|c|c|c|c|c|}
\hline \multicolumn{5}{|c|}{$\begin{array}{c}\text { TABLE-4 } \\
\text { EFFECT OF INTERFERENCE IONS AT LOW AND HIGH LEVELS IN THE DETECTION OF As(III) }\end{array}$} \\
\hline Interfering ion & Concentration $(\mathrm{mg} / \mathrm{L})$ & $\begin{array}{l}\text { Calculated As(III) concentration } \\
\text { Mean } \pm \text { SD }(\mu \mathrm{g} / \mathrm{L})\end{array}$ & Recovery (\%) & $\begin{array}{l}p \text {-value of Paired Sample } \\
t \text {-test }\end{array}$ \\
\hline \multirow[t]{2}{*}{$\mathrm{Ni}^{2+}$} & 0.002 & $10.303 \pm 1.427$ & 103.03 & 0.660 \\
\hline & 0.200 & $11.037 \pm 1.553$ & 110.37 & 0.210 \\
\hline \multirow[t]{2}{*}{$\mathrm{Mg}^{2+}$} & 0.500 & $10.297 \pm 1.496$ & 102.97 & 0.680 \\
\hline & 50.00 & $10.114 \pm 1.132$ & 101.14 & 0.399 \\
\hline \multirow[t]{2}{*}{$\mathrm{Mn}^{2+}$} & 0.005 & $11.293 \pm 1.263$ & 112.93 & 0.084 \\
\hline & 0.500 & $10.33 \pm 2.56$ & 103.30 & 0.790 \\
\hline \multirow[t]{2}{*}{$\mathrm{Al}^{3+}$} & 0.003 & $11.330 \pm 1.704$ & 113.30 & 0.156 \\
\hline & 0.300 & $11.507 \pm 1.911$ & 115.07 & 0.153 \\
\hline \multirow[t]{2}{*}{$\mathrm{Fe}^{3+}$} & 0.002 & $10.79 \pm 1.808$ & 107.90 & 0.384 \\
\hline & 2.000 & $9.384 \pm 1.389$ & 93.84 & 0.378 \\
\hline \multirow[t]{2}{*}{$\mathrm{Na}^{+}$} & 3.000 & $10.26 \pm 1.166$ & 102.60 & 0.644 \\
\hline & 300.0 & $10.713 \pm 1.676$ & 107.13 & 0.396 \\
\hline \multirow[t]{2}{*}{$\mathrm{Cl}^{-}$} & 2.000 & $10.381 \pm 1.881$ & 103.81 & 0.674 \\
\hline & 200.0 & $10.911 \pm 2.034$ & 109.11 & 0.373 \\
\hline \multirow[t]{2}{*}{$\mathrm{SO}_{4}^{2-}$} & 2.000 & $10.94 \pm 2.38$ & 109.40 & 0.428 \\
\hline & 200.0 & $10.506 \pm 1.375$ & 105.06 & 0.457 \\
\hline \multirow[t]{2}{*}{$\mathrm{NO}_{2}^{-}$} & 4.000 & $10.22 \pm 1.290$ & 102.20 & 0.859 \\
\hline & 400.0 & $10.15 \pm 1.032$ & 101.50 & 0.892 \\
\hline \multirow[t]{2}{*}{$\mathrm{NO}_{3}^{-}$} & 0.020 & $10.866 \pm 1.492$ & 108.66 & 0.264 \\
\hline & 2.000 & $10.053 \pm 1.723$ & 100.53 & 0.948 \\
\hline
\end{tabular}

method with the image processing technique can determine the level concentration of As(III) concentration accurately.

\section{Conclusion}

Present method to determine arsenic(III) has been developed based on colorimetric method incorporated with image processing technique. Results indicated that the mean of RGB values were inversely proportional to the concentration of As(III). The final fitted model and the coefficient of RGB values for the presented method were obtained and tested with the accuracy (RBs of 0.5 to $5.2 \%$ ), precision (RSDs of $0.2 \%$ to $4.4 \%)$ and detection limit $(2.24 \mu \mathrm{g} / \mathrm{L})$. For the investigations on the interference with other ions, there is no significant interfere in the determination of $10 \mu \mathrm{g} / \mathrm{L}$ of $\mathrm{As}(\mathrm{III})$ measured by the presented method of this study, using either low or highlevel concentration of the interference ions.

\section{ACKNOWLEDGEMENTS}

The authors express their gratitude to Ministry of Higher Education of Malaysia for the financial support (PRGS/1/2012/ STWN01/UPNM/02/1). The authors also highly appreciated Universiti Pertahanan Nasional Malaysia for providing research facilities to conduct this study.

\section{REFERENCES}

1. K. Shrivas, R. Shankar and K. Dewangan, Sens. Actuators B Chem., 220, 1376 (2015);

https://doi.org/10.1016/j.snb.2015.07.058

2. R. Dominguez-Gonzalez, L. Gonzalez-Varela and P. Bermejo-Barrera, Talanta, 118, 262 (2014);

https://doi.org/10.1016/j.talanta.2013.10.029.
3. L. Song, K. Mao, X. Zhou and J. Hu, Talanta, 146, 285 (2016); https://doi.org/10.1016/j.talanta.2015.08.052.

4. P. Mandal, Emerging Contaminants, 3, 17 (2017); https://doi.org/10.1016/j.emcon.2017.01.004.

5. J. Ma, M.K. Sengupta, D. Yuan and P.K. Dasgupta, Anal. Chim. Acta, 831, 1 (2014); https://doi.org/10.1016/j.aca.2014.04.029.

6. J. Saha, A.D. Roy, D. Dey, J. Nath, D. Bhattacharjee and S.A. Hussain, Sens. Actuators B Chem., 241, 1014 (2017); https://doi.org/10.1016/j.snb.2016.10.098.

7. S.S. Boxi and S. Paria, Dalton Trans., 44, 20464 (2015); https://doi.org/10.1039/C5DT03958D.

8. Y. Kiso, S. Asaoka, Y. Kamimoto, S. Tanimoto and K. Yokota, J. Environ. Chem. Eng., 3, 40 (2015);

https://doi.org/10.1016/j.jece.2014.11.017.

9. J. Leong, K. Ong, W. Zin, F. Anwar, U. Rauf, C. Teoh, H. Ghapor and M. Osman, Orient. J. Chem., 32, 2407 (2016); https://doi.org/10.13005/ojc/320512.

10. M.E. Carro Perez and F.M. Francisca, J. Environ. Sci. Health A, 48, 191 (2013); https://doi.org/10.1080/10934529.2012.717811.

11. U.S. Environmental Protection Agency, Guidelines Establishing Test Procedures for the Analysis of Pollutants (App. B, Part 136, Definition and Procedures for the Determination of Detection Limit Method): U.S. Code of Federal Regulations, Title 40, revised July 1, p. 265 (1997).

12. P. Devi, M. Kaur, S. Chatterji and R. Thakur, International Conference on Recent Advances and Trends in Electrical Engineering (RATEE-2014) p. 167 (2014).

13. S. Hu, J. Lu and C. Jing, J. Environ. Sci. (China), 24, 1341 (2012); https://doi.org/10.1016/S1001-0742(11)60922-4.

14. J. Das and P. Sarkar, Environ. Sci. Water Res. Technol., 2, 693 (2016); https://doi.org/10.1039/C5EW00276A.

15. M. Salman, M. Athar, Waheed-uz-Zaman, U. Shafique, J. Anwar, R. Rehman, S. Ameer and M. Azeem, Anal. Methods, 4, 242 (2012); https://doi.org/10.1039/c1ay05569k.

16. K. Hagiwara, Y. Koike, M. Aizawa and T. Nakamura, Talanta, 144, 788 (2015); https://doi.org/10.1016/j.talanta.2015.07.002. 